\title{
Growth differentiation factor-15 is associated with cardiovascular outcomes in patients with coronary artery disease
}

Man Li ${ }^{1,2}$, Lei Duan², Yu-Lun Cai ${ }^{1,2}$, Hui-Ying Li ${ }^{1,2}$, Ben-Chuan Hao ${ }^{1,2}$, Jian-Qiao Chen ${ }^{1,2}$ and Hong-Bin Liu ${ }^{2,3^{*}}$ (D)

\begin{abstract}
Background: Growth differentiation factor-15 (GDF-15) is a marker of inflammation, oxidative stress and it is associated with adverse prognosis in cardiovascular disease. The aim of the present cohort study is to investigate the prognostic value of GDF-15 in patients with coronary artery disease (CAD) during long-term follow up.

Methods: A total of 3641 consecutive patients with CAD were prospectively enrolled into the study and followed up for major adverse cardiovascular events (MACEs) and all-cause death up to 5.3-7.6 years. Plasma GDF-15 was measured and clinical data and long-term events were registered. The patients were subsequently divided into three groups by the levels of GDF-15 and the prognostic value of GDF-15 level with MACEs and all-cause death was evaluated.

Results: After a median follow-up at 6.4 years later, 775 patients (event rate of 21\%) had developed MACEs and 275 patients died (event rate of 7.55\%). Kaplan-Meier analysis indicated that the patients with GDF-15>1800 ng/L were significantly associated with an increased risk of MACEs and all-cause death. Cox regression analysis indicated that GDF-15>1800 ng/L were independently associated with the composite of MACEs (HR 1.74; 95\% Cl 1.44-2.02; $\mathrm{P}<0.001)$ and all-cause death (HR 2.04; $95 \% \mathrm{Cl} 1.57-2.61 ; \mathrm{P}<0.001)$. For MACEs, GDF-15 significantly improved the C-statistic (area under the curve, 0.583 [95\% $\mathrm{Cl} 0.559-0.606]$ to 0.628 [0.605-0.651]; $\mathrm{P}<0.001$ ), net reclassification index $(0.578 ; \mathrm{P}=0.031)$, and integrated discrimination index $(0.021 ; \mathrm{P}=0.027)$. For all-cause death, GDF-15 significantly improved the C-statistic $(0.728$ [95\% Cl 0.694-0.761] to 0.817 [0.781-0.846]; $\mathrm{P}<0.001)$, net reclassification index $(0.629$; $P=0.001)$, and integrated discrimination index $(0.035 ; P=0.002)$.
\end{abstract}

Conclusions: In the setting of CAD, GDF-15 is associated with long-term MACEs and all-cause death, and provides incremental prognostic value beyond traditional risks factors.

Keywords: Growth differentiation factor-15, Major adverse cardiovascular outcomes, Coronary artery disease

\section{Background}

Cardiovascular (CV) diseases, consisting of ischemic heart disease, stroke, heart failure, peripheral arterial disease, and a number of other cardiac and vascular conditions, remains the leading cause of death of the

\footnotetext{
*Correspondence: liuhbcad301@163.com

2 Department of Cardiology, The Second Medical Center, Chinese PLA General Hospital, Beijing, China

Full list of author information is available at the end of the article
}

world [1]. It is well known that coronary heart disease as a main cause of ischemic heart disease has become a major health concern over the past several decades. Patients with previous coronary heart disease have a high probability of MACEs. Stratification for subsequent coronary events among patients with coronary artery disease (CAD) is of considerable importance because of the potential to guide secondary preventive therapies. Identifying high-risk patients prone to future MACEs may improve prognosis. Conventional risk factors that

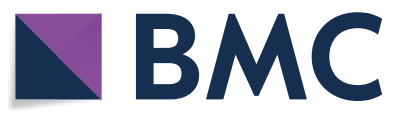

(c) The Author(s) 2020. This article is licensed under a Creative Commons Attribution 4.0 International License, which permits use, sharing, adaptation, distribution and reproduction in any medium or format, as long as you give appropriate credit to the original author(s) and the source, provide a link to the Creative Commons licence, and indicate if changes were made. The images or other third party material in this article are included in the article's Creative Commons licence, unless indicated otherwise in a credit line to the material. If material is not included in the article's Creative Commons licence and your intended use is not permitted by statutory regulation or exceeds the permitted use, you will need to obtain permission directly from the copyright holder. To view a copy of this licence, visit http://creativeco mmons.org/licenses/by/4.0/. The Creative Commons Public Domain Dedication waiver (http://creativecommons.org/publicdomain/ zero/1.0/) applies to the data made available in this article, unless otherwise stated in a credit line to the data. 
include gender, age, smoking, glucose level, blood pressure and cholesterol level have long been used to risk stratify subjects who are at risk of MACEs [2, 3]. However, these clinical risk factors themselves have limited predictive value in patients with CAD. Biomarkers have become increasingly important tools helping to improve patient care over the past two decades. In recent years, cardiac biomarkers have been shown to be increasingly important tools helping to predict cardiovascular risk and superior to models based solely on traditional risk factors $[4,5]$. Growth and differentiation factor 15 (GDF$15)$, previously known as macrophage inhibitory cytokine 1 (MIC-1), is a divergent transforming growth factor $\beta$ (TGF- $\beta$ ) family member historically associated with cancer cachexia, cardiovascular disease, and a host of other diseases with inflammatory etiologies [6]. GDF-15 is expressed in most tissues only at very low levels [7], the only human organ that expresses high levels of GDF-15 in healthy conditions is the placenta [8]. However, GDF-15 could be markedly increased in the case of cardiovascular injury, such as pressure overload, myocardial infarction, heart failure, and atherosclerosis [9-11]. In the past decade, accumulating evidence has demonstrated that the GDF-15 serve as a potential prognostic factor in patients in with acute coronary syndrome [12-14]. However, these studies did not elucidate the long-term prognostic value of MACEs in CAD patients. Therefore, the aim of the present study was to investigate the long-term prognostic value of plasma GDF-15 on all-cause death and MACEs in a large scale patients during a long-term follow up with established CAD.

\section{Methods \\ Study population}

The present study was designed as a single-center, observational cohort study. As described in the flowchart (Fig. 1), from March 2011 to December 2015, 4078 patients who underwent coronary angiography at the Chinese PLA General Hospital were recruited in the study. The patients underwent coronary angiography examination because of angina-like chest pain or positive noninvasive tests (such as treadmill exercise test or coronary computed tomography angiography). The result of angiography suggested at least one major coronary artery stenosis $\geq 50 \%$ was diagnosed as CAD. Then, 83 patients with the detailed data lost and 112 patients without angiographically determined CAD were excluded. 56 patients with congestive heart failure, systematic inflammatory disease, hemodynamically significant valvar heart disease, surgery or trauma within the previous month,

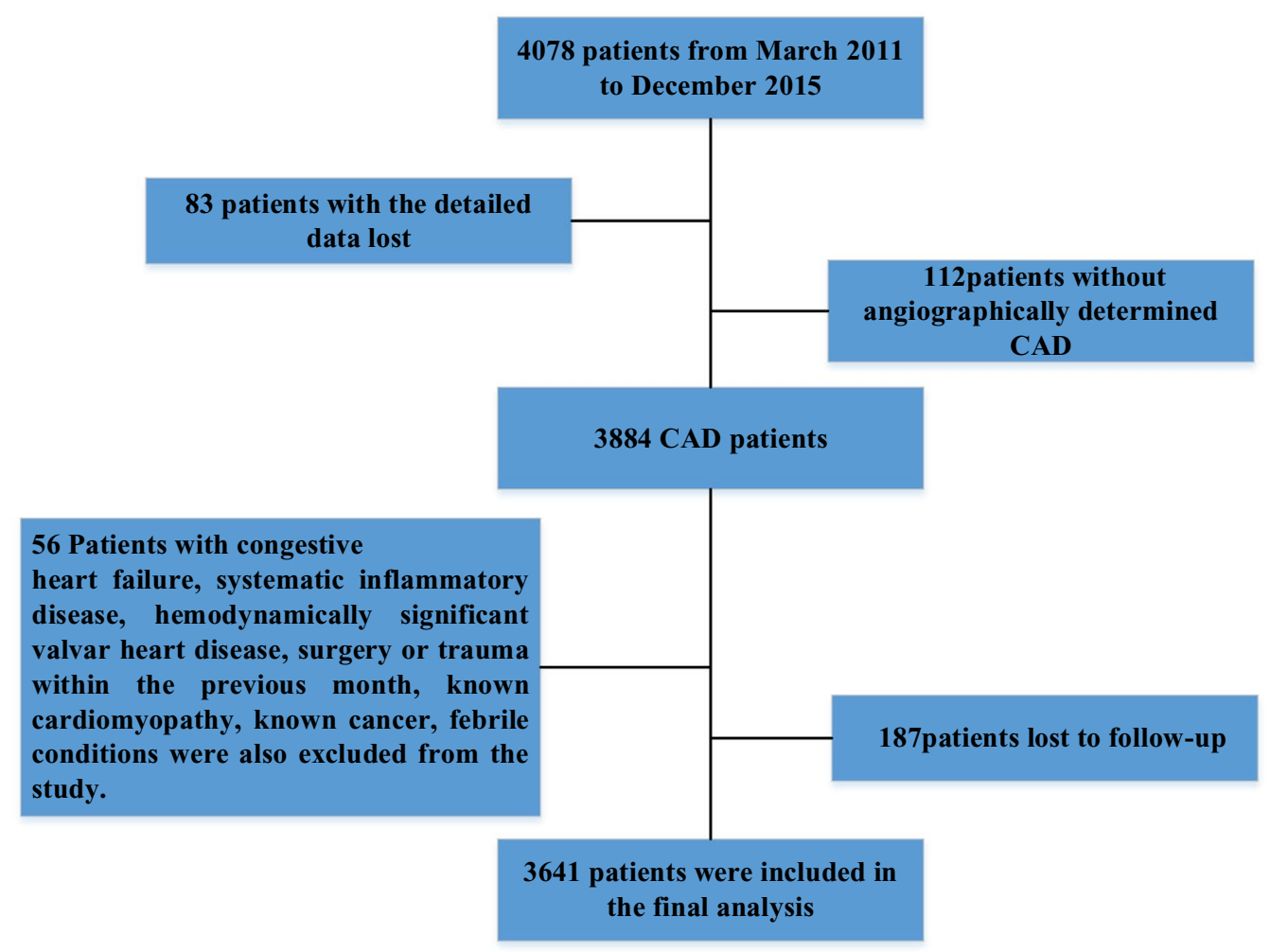

Fig. 1 Flowchart of the study 
known cardiomyopathy, known cancer, febrile conditions were also excluded from the study. 187 patients lost to follow-up were also excluded. Thus, the final study cohort consisted of 3641 patients, 2742 with symptoms of unstable angina or myocardial infarction (MI) and 899 with symptoms of stable angina. All subjects gave written informed consent. This study was approved by the Ethics Board of the Chinese PLA General Hospital and written informed consent was obtained from each patient.

\section{Baseline examinations}

All enrolled patients were required to complete a standardized questionnaire to collect comprehensive data on medical and family history, medication use, smoking status, body weight, height, systolic and diastolic blood pressure. Hypertension was defined as blood pressure $\geq 140 / 90 \mathrm{~mm} \mathrm{Hg}$ or receiving antihypertensive treatment. Hyperlipidemia was defined as known but untreated dyslipidemia or current treatment with lipidlowering medications. Diabetes mellitus was defined as known untreated diabetes and/or use of insulin or oral hypoglycemic agents. Patients were defined as current smoker if they reported any tobacco use in the last 30 days.

\section{Laboratory analyses}

Blood samples were drawn from patients early in the morning after hospital admission. Serum was centrifuged within $30 \mathrm{~min}$, and plasma was stored at $-80{ }^{\circ} \mathrm{C}$ for subsequent analysis. Concentration of GDF-15 was routinely measured by an established available enzyme linked immunosorbent assay kit (pre-commercial Elecsys ${ }^{\circledR}$ assay, measuring range 400-40,000 ng/L; Roche Diagnostics, GmbH, Mannheim, Germany). The detection limit was $400 \mathrm{ng} / \mathrm{L}$, and the intra and inter-assay imprecisions were $<0.9 \%$ and $<2.3 \%$, respectively. All GDF- 15 measurements were performed by investigators that were not aware of patients' characteristics and outcomes. As previously reported, GDF-15 risk categories were defined as low risk $(<1200 \mathrm{ng} / \mathrm{L})$, intermediate $(1200-1800 \mathrm{ng} / \mathrm{L})$ and high risk (>1800 ng/L) [12-15]. Other routine measurements were performed at the participating study centers using standard laboratory techniques.

\section{Follow up and study endpoints}

All data were prospectively collected and entered into a database. All patients were followed up semiannually through telephone interviews or clinic visits. The primary endpoint was the occurrence of MACEs. MACEs was determined as a composite of all-cause mortality, nonfatal such as acute coronary syndrome (ACS), or unplanned revascularization treatment. All deaths were considered cardiac unless a definitive non cardiac cause was established. ACS was defined as the clinical diagnosis of ST-segment elevation myocardial infarction (STEMI), non STEMI, or unstable angina pectoris in accordance with the guidelines of the European Society of Cardiology. Unplanned coronary revascularization was defined as unplanned repeated percutaneous coronary intervention $(\mathrm{PCI})$ or unplanned coronary artery bypass grafting (CABG), with at least 1 of the following: (1) recurrence of angina; (2) positive noninvasive test; and (3) positive invasive physiological test. The second outcome of this study was all-cause death.

\section{Statistical analysis}

Continuous variables were presented as means \pm SDs, while categorical variables were described as percentages. Comparisons between groups were performed by using unpaired Student's $t$ test for continuous variables and the Chi square test or Fisher's exact test for categorical variables. Spearman's correlation coefficients were calculated to evaluate the relations between the levels of GDF-15 and clinical variables. Multiple linear regression was used to determine which covariates were independently associated with GDF-15 levels. For patients who experienced more than one event, the first was considered. Kaplan-Meier analysis was used for stratified analysis of time-to-event for 2 event types: (1) MACEs; (2) overall mortality; and statistical assessment was performed using the log-rank test. The differences in proportions in outcome events in the different strata of GDF-15 levels were judged by Fisher's exact test. The relation of GDF-15 levels to each clinical outcome is presented as cumulative Kaplan-Meier curves and analyzed with Cox proportional hazards models [hazard ratios (HRs) with 95\% CIs] with GDF-15 both with GDF-15 concentration as a continuous variable and with GDF-15 group (G1-G3) as a categorical variable. Simple Cox-regression analysis was used to identify predictors of each clinical outcome during the follow up. A multivariate Cox proportional hazards regression model was used to identify independent predictors of clinical events. Covariates that were either statistically significant on univariate analysis or clinical risk factors were considered candidate variables. Model 1: Clinical background characteristics included age, sex, BMI, smoking, hypertension, diabetes mellitus, and hyperlipidemia. Model 2 includes model 1, with the addition of GDF-15. For illustrative purposes, receiver operating characteristics (ROC) plots were derived from univariable binary logistic regression models. The prognostic discrimination of GDF-15 was assessed by comparing the incremental improvement of the Brier score, Harrell's C-statistic, and by determining the integrated discrimination improvement (IDI) and the net re-classification improvement (NRI) using continuous NRI and 
NRI at the event rate. All probability values were 2 -sided, and $P$ values $<0.05$ were considered statistically significant. STATA 14.2 (Stata Corp, College Station, Texas, USA) and R statistical software version 3.4.4 (R Foundation for Statistical Computing, Vienna, Austria) were used for statistical analysis.

\section{Results}

\section{Patient characteristics}

A total of 3641 patients diagnosed as CAD admitted to our hospital were enrolled in the present study. The median age was 64 years; $56.1 \%$ were male, the median GDF-15 level was $1884 \mathrm{ng} / \mathrm{L}$. The enrolled patients were divided into three groups upon the levels of serum GDF-15 (G1: GDF-15<1200 ng/L, G2: GDF-15:12001800 ng/L, G3: GDF-15 > 1800 ng/L). During 6.4 (median follow-up of 6.4 [interquartile range 5.3-7.6]) years of follow-up, 775 patients had an occurrence of MACEs. In those patients, 158 (15.9\%) had values of GDF-15 below $1200 \mathrm{ng} / \mathrm{L}, 134$ (17.8\%) between 1200 and $1800 \mathrm{ng} / \mathrm{L}$ and $483(25.2 \%)$ above $1800 \mathrm{ng} / \mathrm{L}$. The baseline characteristics of the three groups were shown in Table 1.

Patients with a higher level of GDF-15 were older, had a higher level of total cholesterol (TC), had a history of myocardial infarction and percutaneous coronary intervention or coronary artery bypass graft; and had a higher rate of hypertension, hyperlipidemia, and diabetes. There were no differences between patients included and not included in the analysis regarding other background variables: sex, body mass index (BMI), triglyceride (TG), high density lipoprotein cholesterol (HDL-C), low density lipoprotein cholesterol (LDL-C), smoking and treatment.

\section{Correlations of serum GDF-15 levels with other clinical biochemical factors}

Increasing levels of GDF-15 at presentation were associated with increased age, diabetes, hypertension, hyperlipidemia and a history of previous myocardial infarction and previous PCI/CABG. GDF-15 levels were also related to a lower rate of aspirin use (Table 2). By multiple regression analysis that included all patients' characteristics shown in Table 2, used the natural logarithm of GDF15 as the dependent variable, GDF-15 was independently associated with age $(\mathrm{P}<0.001)$, diabetes $(\mathrm{P}<0.001)$.

\section{Clinical outcomes \\ Primary endpoint}

A composite of major adverse cardiovascular events was analyzed during follow-up (Fig. 1).

In this way, 775 patients had an occurrence of MACEs. Of those patients, 158 (15.9\%) had values of GDF15 below $1200 \mathrm{ng} / \mathrm{L}, 134$ (17.8\%) between 1200 and $1800 \mathrm{ng} / \mathrm{L}$ and 483 (25.2\%) above $1800 \mathrm{ng} / \mathrm{L}$. The MACEs rate was significantly higher in the group of patients with GDF-15 values $>1800 \mathrm{ng} / \mathrm{L}$ compared with those with GDF-15 levels between 1200 and $1800 \mathrm{ng} / \mathrm{L}$ and patients

Table 1 Baseline clinical and laboratory characteristics of the study patients according to status of GDF-15

\begin{tabular}{|c|c|c|c|c|c|}
\hline & Total $n=3641$ & $\begin{array}{l}\text { Low GDF-15 } \\
(<1200 \mathrm{ng} / \mathrm{L}) \\
(\mathrm{n}=991)\end{array}$ & $\begin{array}{l}\text { Medium GDF-15 }(1200- \\
1800 \mathrm{ng} / \mathrm{L})(\mathrm{n}=750)\end{array}$ & $\begin{array}{l}\text { High GDF-15 } \\
(>1800 \mathrm{ng} / \mathrm{L}) \\
(\mathrm{n}=1900)\end{array}$ & $P$ value for trend \\
\hline Age, years & $61.4(27-95)$ & $57.2(26-95)$ & $59.9(30-92)$ & $64.3(27-95)$ & $<0.001$ \\
\hline Male, n (\%) & $2632(72.29)$ & $735(74.17)$ & $540(53.33)$ & $1357(71.42)$ & 0.484 \\
\hline $\mathrm{BMI}(\mathrm{kg} / \mathrm{m} 2)$ & $25.64(13.3-41)$ & $26.02(13.3-41)$ & $25.82(16.5-37.4)$ & $25.38(17.5-32.1)$ & 0.074 \\
\hline Current smokers, n (\%) & $1668(45.82)$ & $473(47.72)$ & $345(46.00)$ & $850(44.70)$ & 0.304 \\
\hline Hypertension, n (\%) & $2370(65.09)$ & $592(59.74)$ & $474(63.20)$ & $1304(68.63)$ & $<0.001$ \\
\hline Hyperlipidemia, n (\%) & $1120(30.76)$ & $282(28.5 \%)$ & $230(30.70)$ & $608(32.0)$ & 0.034 \\
\hline Diabetes mellitus, n (\%) & $1163(31.94)$ & $223(22.50)$ & $226(30.13)$ & $714(37.58)$ & $<0.001$ \\
\hline Previous MI, n (\%) & $254(6.98)$ & $54(5.45)$ & $44(5.89)$ & $156(8.21)$ & $<0.001$ \\
\hline Previous PCI/CABG, n (\%) & $299(8.21)$ & $66(6.66)$ & $57(7.58)$ & $176(9.26)$ & $<0.001$ \\
\hline $\mathrm{TC}(\mathrm{mmol} / \mathrm{L})$ & $4.03 \pm 1.0$ & $3.97 \pm 1.02$ & $4.03 \pm 1.09$ & $4.10 \pm 1.14$ & 0.046 \\
\hline $\mathrm{HDL}-\mathrm{C}(\mathrm{mmol} / \mathrm{L})$ & $1.07 \pm 0.68$ & $1.06 \pm 0.43$ & $1.09 \pm 0.94$ & $1.07 \pm 0.67$ & 0.624 \\
\hline LDL-C (mmol/L) & $2.40 \pm 0.91$ & $2.36 \pm 0.84$ & $2.44 \pm 0.90$ & $2.40 \pm 0.96$ & 0.201 \\
\hline TG (mmol/L) & $1.62 \pm 1.21$ & $1.65 \pm 1.11$ & $1.66 \pm 1.05$ & $1.60 \pm 1.32$ & 0.326 \\
\hline \multicolumn{6}{|l|}{ Medications } \\
\hline Aspirin, n (\%) & 3415 (93.79\%) & 942 (95.06\%) & 718 (95.73\%) & 1755 (92.37\%) & 0.067 \\
\hline ACEI, n (\%) & 1503 (41.28\%) & $403(40.67 \%)$ & 305 (40.67\%) & $822(43.26 \%)$ & 0.289 \\
\hline ß-blocker, n (\%) & 1629 (44.74\%) & 744 (75.08\%) & 533 (71.07\%) & 1352 (71.16\%) & 0.070 \\
\hline Statins, n (\%) & 3442 (94.53\%) & $944(95.25 \%)$ & 716 (95.47\%) & 1782 (93.79\%) & 0.070 \\
\hline
\end{tabular}


Table 2 Spearman's correlation coefficients between GDF15 and clinical and biochemical parameters

\begin{tabular}{|c|c|c|}
\hline & \multicolumn{2}{|c|}{ Spearman correlation } \\
\hline & Coefficient & $\mathbf{P}$ \\
\hline Age, years & 0.267 & $<0.001$ \\
\hline Male, n (\%) & -0.025 & 0.133 \\
\hline $\mathrm{BMI}\left(\mathrm{kg} / \mathrm{m}^{2}\right)$ & -0.024 & 0.100 \\
\hline Current smokers, n (\%) & -0.025 & 0.127 \\
\hline Hypertension, n (\%) & 0.079 & $<0.001$ \\
\hline Hyperlipidemia, n (\%) & 0.053 & 0.031 \\
\hline Diabetes mellitus, n (\%) & 0.137 & $<0.001$ \\
\hline Previous MI, n (\%) & 0.064 & $<0.001$ \\
\hline Previous PCI/CABG, n (\%) & 0.096 & $<0.001$ \\
\hline $\mathrm{TC}(\mathrm{mmol} / \mathrm{L})$ & 0.017 & 0.315 \\
\hline $\mathrm{HDL}-\mathrm{C}(\mathrm{mmol} / \mathrm{L})$ & 0.007 & 0.656 \\
\hline $\mathrm{LDL}-\mathrm{C}(\mathrm{mmol} / \mathrm{L})$ & 0.014 & 0.403 \\
\hline $\mathrm{TG}(\mathrm{mmol} / \mathrm{L})$ & -0.022 & 0.192 \\
\hline \multicolumn{3}{|l|}{ Medications } \\
\hline Aspirin, n (\%) & -0.057 & 0.001 \\
\hline ACEI, n (\%) & 0.025 & 0.134 \\
\hline$\beta$-blocker, n (\%) & -0.031 & 0.050 \\
\hline Statins, n (\%) & -0.032 & 0.055 \\
\hline
\end{tabular}

with GDF- 15 values $<1200 \mathrm{ng} / \mathrm{L}$ ( $25.2 \%$ vs $17.8 \%$ vs $15.9 \%$, $\mathrm{P}<0.001)$. Kaplan-Meier curve of the incidence of the primary endpoint is presented in Fig. 2a. The incidence of the primary endpoint in the G3 group was significantly higher than that in the G1, G2 group (log-rank $\mathrm{P}<0.001$ ). Univariate Cox proportional analyses revealed that GDF15 values $>1800 \mathrm{ng} / \mathrm{L}$ were significantly associated with the incidence of MACEs (unadjusted $\mathrm{HR}=1.92 ; 95 \%$ CI 1.37-2.52; $\mathrm{P}<0.001)$. After adjusted for basic clinical risk factors (age, sex, smoking hypertension, body mass index, diabetes mellitus and hyperlipidemia), in multivariate analysis, GDF-15 values $>1800 \mathrm{ng} / \mathrm{L}$ was associated with the incidence of MACEs with an HR of 1.74 (95\% CI 1.44-2.02; $\mathrm{P}<0.001$ ) (Table 3).

\section{Secondary endpoint}

During 6.4 years of follow-up (median follow-up of 6.4 [interquartile range 5.3-7.6] years), 275 patients died. Patients with GDF-15 levels $<1200 \mathrm{ng} / \mathrm{L}$ had a low mortality rate of $3.2 \%$ (32). Patients with GDF-15 levels between 1200 and $1800 \mathrm{ng} / \mathrm{L}$ had the same mortality rate of $3.2 \%$ (24), whereas those with GDF-15 levels $>1800 \mathrm{ng} / \mathrm{L}$ had a very high mortality rate of $11.3 \%$ (219) $(\mathrm{P}<0.001)$. Kaplan-Meier curve of the incidence of the primary endpoint is presented in Fig. 2b. The incidence of all-cause death the G3 group was significantly higher than that in the G1, G2 group (P log-rank $<0.001$ ).
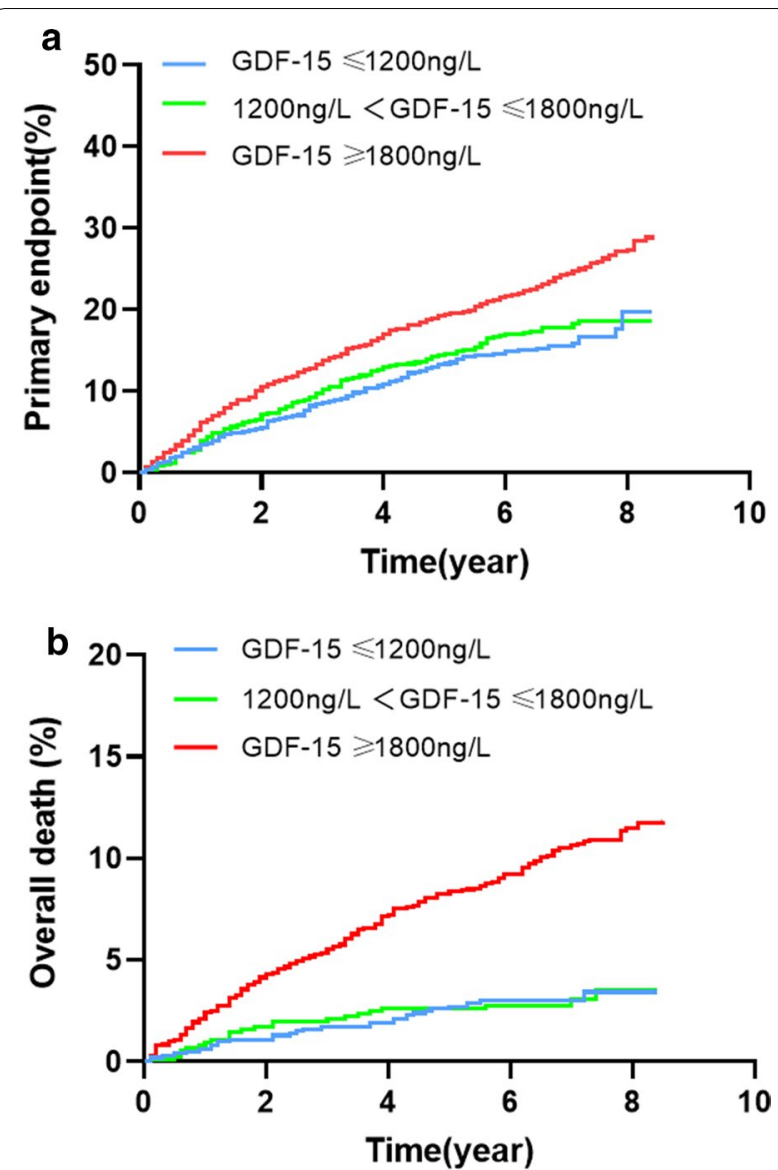

Fig. 2 Kaplan-Meier analysis according to different levels of GDF-15

Univariate Cox proportional analyses revealed that GDF$15>1800 \mathrm{ng} / \mathrm{L}$ were significantly associated with the incidence of all-cause death (Table 3). After adjustment for potential confounders, in multivariate analysis, higher GDF-15 values $>1800 \mathrm{ng} / \mathrm{L}$ were still independently associated with all-cause death (adjusted HR 2.04; 95\% CI 1.57-2.61; $\mathrm{P}<0.001$ ) (Table 4).

Incremental value of GDF-15 over conventional risk factors for MACEs

We analyzed the predictive value of GDF-15 by ROC curve. For MACEs: ROC curve analyses indicated that $\mathrm{C}$ index (area under the curve) was 0.583 (95\% CI 0.559 0.606) for clinical model (model1), 0.595 (95\% CI $0.594-$ 0.641) for GDF-15 alone, 0.628 (95\% CI 0.605-0.651) for clinical model including GDF-15 (model2). ROC curve analysis showed non-significant differences in the clinical model alone compared with GDF-15 alone $(\mathrm{P}=0.093)$, however, there was a significant difference compared to the clinical model with GDF-15 (P<0.001, Fig. 3a). Furthermore, Model 2 showed a significantly improved net reclassification improvement (0.578) and IDI (0.021), 
Table 3 Relation of the GDF-15 level and MACEs in univariate and multivariate survival analysis

\begin{tabular}{|c|c|c|c|c|c|c|}
\hline & \multicolumn{6}{|c|}{ Independent predictors of major adverse cardiac events } \\
\hline & \multicolumn{3}{|c|}{ Univariate models } & \multicolumn{3}{|c|}{ Multivariate models } \\
\hline & HR & $95 \% \mathrm{Cl}$ & $\mathbf{P}$ & HR & $95 \% \mathrm{Cl}$ & $\mathbf{P}$ \\
\hline Age & 1.02 & $1.013-1.026$ & 0.00 & 1.02 & $1.009-1.022$ & 0.00 \\
\hline Sex & 0.00 & $0.001-0.028$ & 0.00 & 0.01 & $0.001-0.057$ & 0.00 \\
\hline Smoking & 1.10 & $0.933-1.296$ & 0.23 & - & - & - \\
\hline BMI & 0.98 & $0.959-1.000$ & 0.05 & 1.00 & $0.977-1.020$ & 0.89 \\
\hline Hypertension & 1.03 & $0.646-0.880$ & 0.00 & 0.82 & $0.703-0.967$ & 0.02 \\
\hline Hyperlipidemia & 1.15 & $0.98-1.34$ & 0.09 & - & - & - \\
\hline DM & 0.79 & $0.680-0.911$ & 0.00 & 0.89 & $0.767-1.032$ & 0.14 \\
\hline GDF-15 $\leq 1200 \mathrm{ng} / \mathrm{L}$ & 1.05 & $0.87-1.44$ & 0.16 & - & - & - \\
\hline $1200<\mathrm{GDF}-15 \leq 1800 \mathrm{ng} / \mathrm{L}$ & 1.09 & $0.90-1.65$ & 0.08 & - & - & - \\
\hline GDF-15 > 1800 ng/L & 1.92 & $1.37-2.52$ & $<0.001$ & 1.74 & $1.44-2.02$ & $<0.001$ \\
\hline
\end{tabular}

Table 4 Relation of the GDF-15 level and all-cause death in univariate and multivariate survival analysis

\begin{tabular}{|c|c|c|c|c|c|c|}
\hline & \multicolumn{6}{|c|}{ Independent predictors of all-cause death } \\
\hline & \multicolumn{3}{|c|}{ Univariate Models } & \multicolumn{3}{|c|}{ Multivariate Models } \\
\hline & HR & $95 \% \mathrm{Cl}$ & $\mathbf{P}$ & HR & $95 \% \mathrm{Cl}$ & $\mathbf{P}$ \\
\hline Age & 1.97 & $1.04-1.12$ & $<0.001$ & 1.07 & $1.01-1.09$ & 0.01 \\
\hline Sex & 1.23 & $0.98-1.37$ & 0.09 & - & - & - \\
\hline Smoking & 0.87 & $0.80-1.17$ & 0.39 & - & - & - \\
\hline BMl & 0.99 & $0.95-1.02$ & 0.48 & - & - & - \\
\hline Hypertension & 0.98 & $0.74-1.28$ & 0.87 & - & - & - \\
\hline Hyperlipidemia & 1.54 & $1.38-1.76$ & 0.02 & 1.48 & $1.38-1.86$ & 0.03 \\
\hline DM & 1.11 & $0.87-1.42$ & 0.42 & - & - & - \\
\hline GDF-15 $\leq 1200 \mathrm{ng} / \mathrm{L}$ & 1.11 & $0.87-1.42$ & 0.42 & - & - & - \\
\hline GDF-15 $\leq 1800 \mathrm{ng} / \mathrm{L}$ & 1.33 & $0.94-1.56$ & 0.13 & - & - & - \\
\hline GDF-15 > $1800 \mathrm{ng} / \mathrm{L}$ & 2.54 & $1.99-3.09$ & $<0.001$ & 2.04 & $1.57-2.61$ & $<0.001$ \\
\hline
\end{tabular}

compared with model 1 (Fig. 3). For all-cause mortality: ROC curve analyses indicated that $\mathrm{C}$ index were 0.728 (95\% CI 0.694-0.761) for clinical model (model1) 0.766 (95\% CI 0.735-0.798) for GDF-15 alone, 0.817 (95\% CI 0.787-0.846) for clinical model including GDF-15. ROC curve analysis showed significant differences in the clinical model alone compared to the clinical model with GDF-15 alone $(\mathrm{P}<0.001)$, and there was a significant difference compared to the clinical model with GDF-15 $(\mathrm{P}<0.001$, Fig. $3 \mathrm{~b})$. Moreover, Model2 showed a significantly improved net reclassification improvement (0.629) and IDI (0.035), compared with model 1 (Fig. 3).

\section{Prognostic value of GDF-15 in long-term and short-term} During the follow up of 0-6 months, 80 patients had the occurrence of MACEs and 31 patients died. During the follow up of 6-12 months, 98 patients had the occurrence of MACEs and 33 patients died. During the follow up of 12-72 months, 501 patients had the occurrence of MACEs and 174 patients died (Fig. 4a, c). And the MACEs rates in 0-6 months, 6-12 months, $12-72$ months were $2.20 \%, 2.68 \%, 14.47 \%$ respectively (Fig. 4b). All-cause death rates in 0-6 months, 6-12 months, $12-72$ months were $0.85 \%, 0.91 \%, 4.86 \%$ (Fig. 4d). To evaluate the prognostic value of GDF-15, we also performed the Kaplan-Meier analysis upon different GDF-15 levels. The results indicated that the patients with GDF-15>1800 ng/L were significantly associated with an increased risk of all-cause death (log rank $\mathrm{P}=0.021$ ) in $0-6$ months. But for MACEs, no significant difference was seen in $0-6$ months $(\log \operatorname{rank} P=0.067)$. However, by the time of 12 months, the patients with GDF-15 $>1800 \mathrm{ng} / \mathrm{L}$ were significantly associated with an increased risk of all-cause death ( $\log$ rank $\mathrm{P}<0.001)$ and MACEs (log rank $\mathrm{P}<0.001)$, the results were the same when they were followed up for 6 years (Fig. 5). 


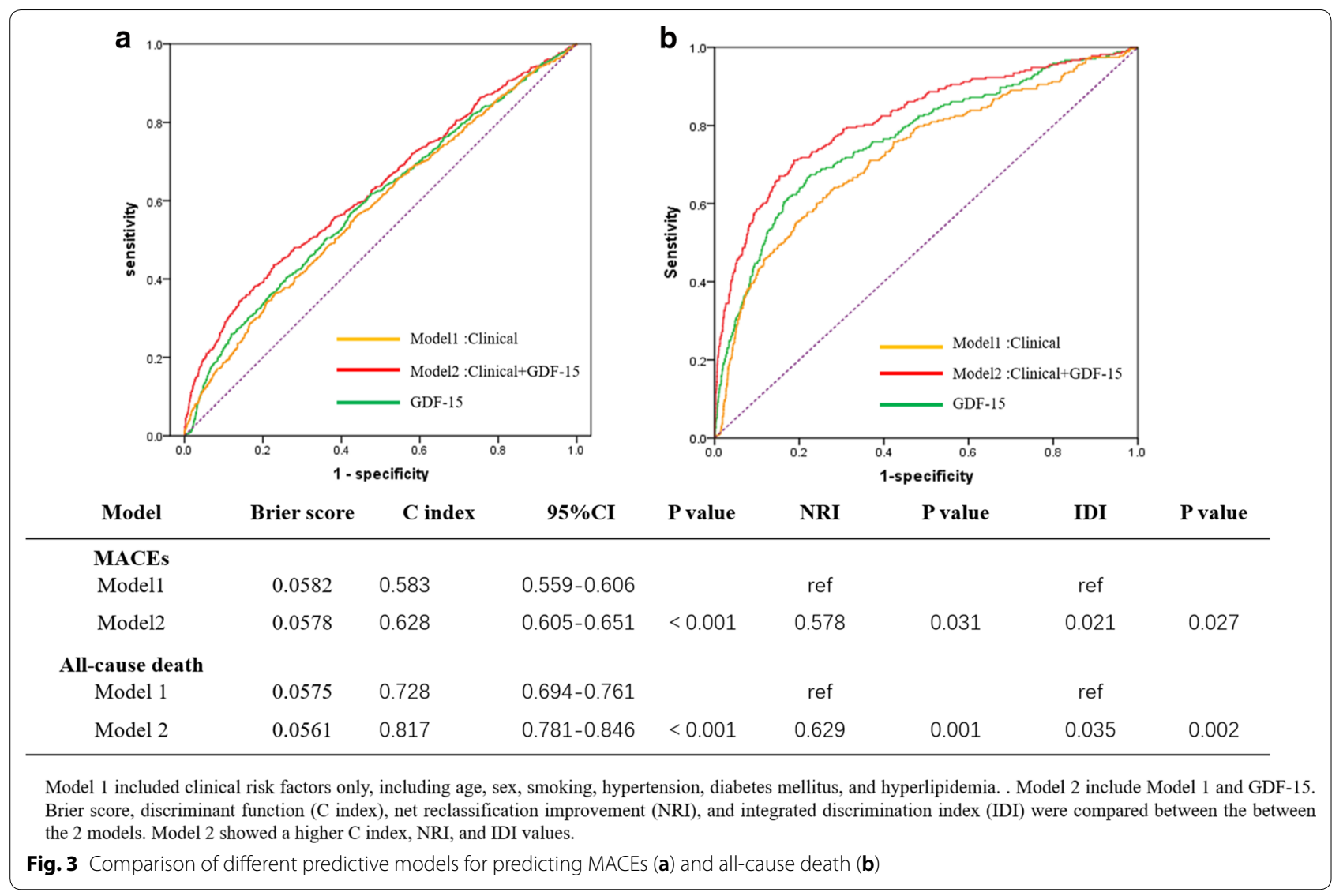

\section{Discussion}

In this study, we found that GDF-15 concentrations higher than $1800 \mathrm{ng} / \mathrm{L}$ were associated with an increased risk of all-cause death and MACEs in patients with established CAD. After adjusting for both established risk factors for CV disease and these other prognostic biomarkers, GDF-15 remained an independent indicator of MACEs and all-cause death (Fig. 6). Even more, we observed that GDF-15 provided an incremental prognostic value beyond a clinical model for MACEs and all-cause death. Besides, our research added new evidence for the short-term predictive value of GDF-15 for CAD patients. Finally, higher GDF-15 concentrations in the setting of established CAD were consistently related with an increased prevalence of cardiovascular risk factors, the result is in consistent with previous studies [16]. Our results provide updated information on the short-term and long-term prognostic role of GDF-15 in CAD, our result indicates that the addition of plasma GDF-15 measurements to information from clinical characteristics and established CV risk factors might further improve risk stratification.

\section{Inflammation and cardiac outcomes}

Inflammatory processes are thought to actively trigger the development of $\mathrm{CV}$ disease and eventual clinical events. Many inflammatory cells such as neutrophils and macrophages might strongly influence atherosclerotic plaque stability, subsequently trigger acute thrombotic vascular disease, including myocardial infarction, stroke, and sudden cardiac death [17-19]. Many pro-inflammatory factors may influence cardiac remodeling as well as development of heart failure [20]. For instance, Cyr61 levels lead to augmented troponin and lower ejection fraction, and was independently associated with adverse cardiac outcomes [21]. Monocytes cells have been extensively proven to predict the incidence of myocardial infarction, the risk of MACEs also negative post-ischemic ventricular remodeling [22]. Moreover, inflammation is involved in cardiac muscle damage, neutrophils drive the early inflammatory response following a myocardial damage [23] and pro-inflammatory interleukins IL-6, IL-18 and MMP-12 are markers of preclinical cardiovascular organ damage [24]. Therefore, inflammation is involved in atherosclerotic plaque rupture, myocardial 

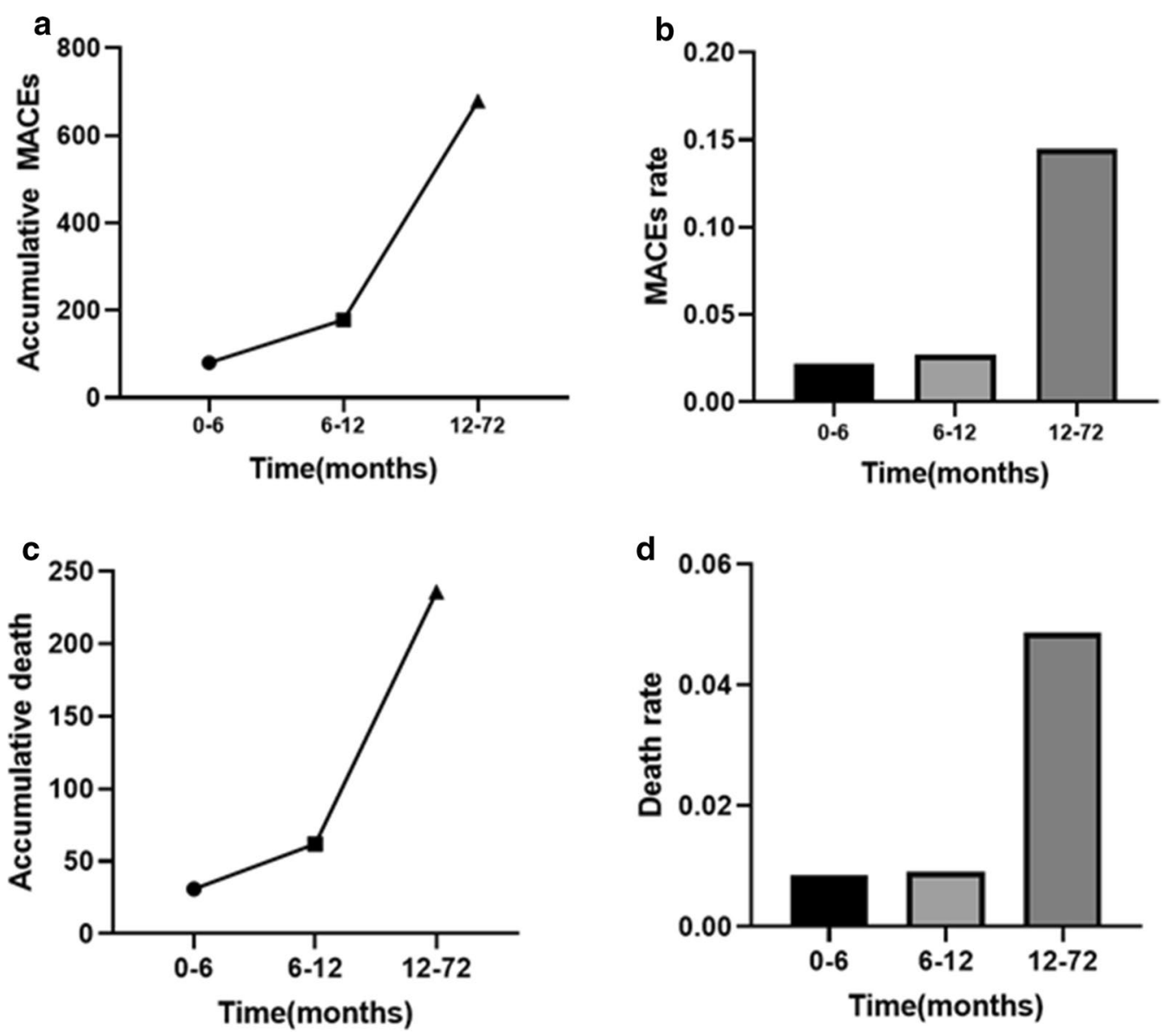

Fig. 4 Accumulative MACEs (a) and death events (c) on 6 months, 12 months and 72 months, the MACEs (b) and death rates (d) during 0-6 months, 6-12 months and 12-72 months

remodeling, myocardial injury, and other cardiac pathological processes, thus playing an important role in the outcome of cardiovascular disease.

\section{GDF-15 and potential mechanisms}

Growth differentiation factor-15 (GDF-15), previous known as NSAID-activated gene 1 (NAG-1) and MIC-1, is a divergent TGF- $\beta$ family member historically associated with cardiovascular disease and a host of other diseases with inflammatory etiologies $[6,25]$. It has been reported as an inflammation-induced central mediator of tissue tolerance and it increases during tissue injury and inflammatory states [6]. A large number of studies have shown that GDF-15 increases in response to various stressors including reactive oxygen species and pro-inflammatory cytokines [26-28]. Besides, GDF-15 is highly expressed in response to different kinds of cytokines and growth factors like interleukin-1 (IL-1), tumor necrosis factor- (TNF-), angiotensin II, macrophage colony stimulating factor (M-CSF), and
TGF- [29-31]. Tumor suppressor protein p53 also induces GDF-15 and thus acting as a growth inhibitory molecule in tissue [32]. Moreover, it has been reported that GDF-15 induced pro-inflammatory factors such as IL- $1 b$, tumor necrosis factor- $\alpha$, and CRP induce GDF15 expression in macrophage cells through the regulation of p53 binding sites in the GDF-15 promoter [33]. The above studies have shown that GDF-15 is induced in inflammatory conditions, and GDF-15 is necessary for survival in inflammation conditions [6]. Therefore, we think GDF-15 might promote tissue protection from inflammatory damage thus playing an important role in the cardiac protection. But beyond that, a growing body of evidence supports that low circulating testosterone are correlated with adverse cardiovascular outcomes, including a higher incidence of CAD and increased cardiovascular and all-cause mortality [34]. It has been reported that in male patients with CAD, high GDF-15 levels are associated with testosterone deficiency supporting the idea that upregulation of GDF-15 in the presence of low 

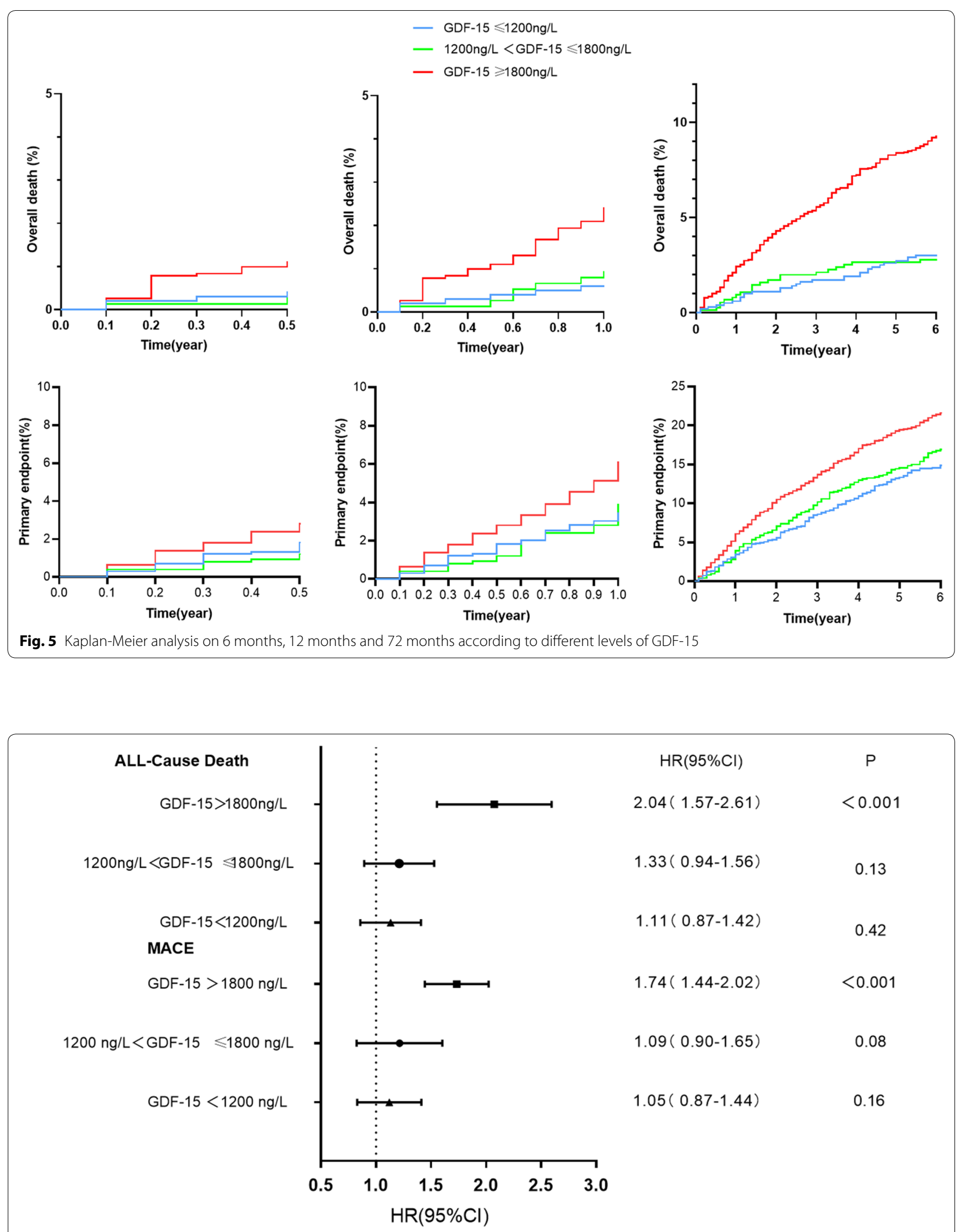

$\begin{array}{cc}H R(95 \% \mathrm{Cl}) & P \\ 2.04(1.57-2.61) & <0.001 \\ 1.33(0.94-1.56) & 0.13 \\ 1.11(0.87-1.42) & 0.42 \\ 1.74(1.44-2.02) & <0.001 \\ 1.09(0.90-1.65) & 0.08 \\ 1.05(0.87-1.44) & 0.16\end{array}$

Fig. 6 Hazard ratios, 95\% confidence intervals (Cl) according to values of GDF-15 
testosterone is a potential mechanism by which GDF-15 affects CAD [35, 36]. Therefore, whether GDF-15 plays a role in cardiovascular protection by affecting testosterone levels or mainly through inflammatory response pathways, its intrinsic mechanism needs to be further elucidated.

\section{GDF-15 and cardiac outcomes}

The prognostic value of GDF-15 has been reported for various cardiovascular diseases, such as ACS, atrial fibrillation, and heart failure [12, 14, 15, 37, 38]. Lindholm had reported a study included 17095 patients with acute coronary syndrome, GDF-15 was the strongest marker associated with all-cause death [14]. According to Kempf T's research, GDF-15 provided prognostic information in STEMI [12]. The predictive value of GDF-15 in ACS has been confirmed in the 2 large non-ST-segment-elevation ACS (NSTE-ACS) trials: the GUSTO-IV (Global Utilization of Strategies to Open Occluded Arteries IV) and FRISC II (Fast Revascularization during Instability in Coronary Artery Disease II) cohorts [12, 15]. Sharma A reported in the ARISTOTLE trial which included 18201 patients with atrial fibrillation that GDF-15 was the strongest marker associated with bleeding death [37]. According to Bouabdallaoui N 's research baseline GDF15 and changes of GDF-15 at both 1 month and 8 months were associated with subsequent mortality and CV events in patients with heart failure in the PARADIGMHF trial [38]. GDF15 could be an integrative biomarker of heart failure in patient with AMI [39]. Moreover, in patients with ambulatory heart failure and reduced ejection fraction, GDF-15 is strongly associated with mortality and adverse cardiovascular outcomes [38]. Through the above researches, GDF-15 appears to be a promising biomarker for individual $\mathrm{CV}$ risk stratification. A lot of researches indicated that, GDF-15 together with a variety of markers may have a higher diagnostic value [12, 40, 41]. GDF-15 should probably be considered as a component of a multiple biomarkers' cardiovascular score for future implementation in clinical practice [42].

According to previous researches, patients were divided into three groups: $<1200,1200-1800$, and $>1800 \mathrm{ng} / \mathrm{L}[12,15]$, our research also divided our patients into three groups according to the GDF-15 levels, however, our result revealed that only GDF-15 values $>1800 \mathrm{ng} / \mathrm{L}$ were significantly associated with the incidence of MACEs in CAD patients. A research measured plasma GDF-15 in 3219 participants of the Dallas Heart Study, their result showed that GDF-15 > $1800 \mathrm{ng} / \mathrm{L}$ was associated with all-cause mortality (HR 3.5; 95\% CI 2.1-5.9, $\mathrm{P}<0.0001$ ), and cardiovascular mortality (HR 2.5; 95\% CI 1.1-5.8, $\mathrm{P}=0.03$ ). Our study is consistent with the results of this study [43]. We add new evidence that GDF-15>1800 ng/L maybe a high risk critical range for patients with coronary heart disease. According to our research, GDF-15 levels are predictive of both long-term MACEs and all-cause death, while GDF-15 can only predict all-cause death in the short-term. Previous studies have shown that GDF-15 has a short-term predictive value for ACS patients and a long-term prognostic value in stable CAD patients. Increased levels of GDF-15 were associated with a higher risk of death during 1-year follow-up in 741 STEMI patients [12]. Another study recruited 1142 patients with NSTEMI or STEMI were follow-up for 1.4 years, the result indicated that GDF-15 is a new marker for predicting death and heart failure in post-AMI patients [44]. Bonaca et al. reported 3501 patients with NSTE-ACS or STEMI were followed up 2 years, GDF-15 is associated with recurrent events after ACS [45]. A total of 1352 patients with stable angina pectoris were followed 3.6 years [46]. Hagström et al. reported that GDF-15 was independently associated with mortality in 14577 patients with stable CAD during a follow up of 3.7 years [47]. According to the above studies, GDF-15 has a short-term predictive value for ACS patients and a long-term prognostic value in stable CAD patients. While the result of our research shows that GDF-15 levels are predictive of both long-term MACEs and all-cause death, and GDF-15 can only predict allcause death in the short-term. Our results also add new evidence for the short-term predictive value of GDF-15 for CAD patients.

In conclusion, our research reveals the pathophysiological pathways of GDF-15 underlying CAD. Higher level of GDF-15 can predict the MACEs events and mortality for CAD patients, GDF-15 values $>1800 \mathrm{ng} / \mathrm{L}$ may be a critical value with a strong prognostic value. Proper reference ranges of GDF-15 need to be established to identify the disease severity and risk stratification of the diseases. Our study provides evidence for the high risk values range and add new evidence for the short-term predictive value of GDF-15 for CAD patients. But whether GDF15 plays a role in cardiovascular protection by affecting testosterone levels or mainly through inflammatory response pathways, its intrinsic mechanism needs to be further elucidated. GDF-15 appears to be a promising biomarker for individual cardiovascular risk stratification, but a combination with other biomarkers may have higher predictive value for cardiovascular disease.

\section{Conclusions}

In conclusion, this large sample size and long-term follow-up study indicated that in the setting of CAD, GDF15 is associated with long-term all-cause death, MACEs and provides incremental prognostic value beyond traditional risks factors. 


\begin{abstract}
Abbreviations
GDF-15: Growth differentiation factor-15; CAD: Coronary artery disease; MACEs: Major adverse cardiovascular events; CV: Cardiovascular; MI: Myocardial infarction; AMI: Acute myocardial infarction; ACS: Acute coronary syndrome; STEMI: ST-segment elevation myocardial infarction; M-CSF: Macrophage colony stimulating factor; TGF- $\beta$ : Transforming growth factor- $\beta$; IL-1: Interleukin-1; TNF-: Tumor necrosis factor-; MIC-1: Macrophage inhibitory cytokine 1; HR: Hazard ratios; ROC: Receiver operator characteristic; PCl: Percutaneous coronary intervention; CABG: Coronary artery bypass grafting; TGF-b: Transforming growth factor b; TC: Total cholesterol; TG: Triglyceride; HDL-C: High density lipoprotein cholesterol; LDL-C: Low density lipoprotein cholesterol; IDI: Integrated discrimination improvement; NRI: Net re-classification improvement.
\end{abstract}

\section{Acknowledgements}

Not applicable.

\section{Authors' contributions}

$\mathrm{HL}$ and $\mathrm{ML}$ designed the study and provided methodological expertise. ML drafted the manuscript. LD, YC, BH, HL, JC drafted the tables and figures and performed statistical analysis. All authors read and approved the final manuscript.

\section{Funding}

This work was supported by the Key Projects of Logistics Scientific Research Project of Chinese PLA (17BJZ48) and the National Key Research Program of China (2017YFC0840103).

\section{Availability of data and materials}

The datasets used and/or analyzed during the current study are available from the corresponding author on reasonable request.

\section{Ethics approval and consent to participate}

This study was approved by the Ethics Board of the Chinese PLA General Hospital and written informed consent was obtained from each patient.

\section{Consent for publication}

Not applicable.

\section{Competing interests}

The authors declare that they have no competing interests.

\section{Author details}

${ }^{1}$ Medical School of Chinese PLA, Beijing, China. ${ }^{2}$ Department of Cardiology, The Second Medical Center, Chinese PLA General Hospital, Beijing, China. ${ }^{3}$ Beijing Key Laboratory of Chronic Heart Failure Precision Medicine, Beijing, China.

Received: 1 May 2020 Accepted: 25 July 2020

Published online: 03 August 2020

\section{References}

1. Mensah GA, Roth GA, Fuster V. The global burden of cardiovascular diseases and risk factors: 2020 and beyond. J Am Coll Cardiol. 2019;74(20):2529-32.

2. Wilson PW, D'Agostino RB, Levy D, Belanger AM, Silbershatz H, Kannel WB. Prediction of coronary heart disease using risk factor categories. Circulation. 1998;97(18):1837-47.

3. Goff DC, Lloyd-Jones DM, Bennett G, Coady S, D'Agostino RB, Gibbons R, et al. 2013 ACC/AHA guideline on the assessment of cardiovascular risk: a report of the American College of Cardiology/American Heart Association Task Force on Practice Guidelines. J Am Coll Cardiol. 2014;63(25 Pt B):2935-59.

4. Wang TJ, Gona P, Larson MG, Tofler GH, Levy D, Newton-Cheh C, et al. Multiple biomarkers for the prediction of first major cardiovascular events and death. N Engl J Med. 2006;355(25):2631-9.
5. Zethelius B, Berglund L, Sundström J, Ingelsson E, Basu S, Larsson A, et al. Use of multiple biomarkers to improve the prediction of death from cardiovascular causes. N Engl J Med. 2008;358(20):2107-16.

6. Luan HH, Wang A, Hilliard BK, Carvalho F, Rosen CE, Ahasic AM, et al. GDF15 is an inflammation-induced central mediator of tissue tolerance. Cell. 2019;178(5):1231-44.

7. Xu J, Kimball TR, Lorenz JN, Brown DA, Bauskin AR, Klevitsky R, et al. GDF15/MIC-1 functions as a protective and antihypertrophic factor released from the myocardium in association with SMAD protein activation. Circ Res. 2006;98(3):342-50.

8. Lawton LN, Bonaldo MF, Jelenc PC, Qiu L, Baumes SA, Marcelino RA, et al. Identification of a novel member of the TGF-beta superfamily highly expressed in human placenta. Gene. 1997;203(1):17-26.

9. Wollert KC, Kempf T, Wallentin L. Growth differentiation factor 15 as a biomarker in cardiovascular disease. Clin Chem. 2017;63(1):140-51.

10. Lok SI, Winkens B, Goldschmeding R, van Geffen AJP, Nous FMA, van Kuik J, et al. Circulating growth differentiation factor-15 correlates with myocardial fibrosis in patients with non-ischaemic dilated cardiomyopathy and decreases rapidly after left ventricular assist device support. Eur J Heart Fail. 2012;14(11):1249-56.

11. Kempf T, Zarbock A, Widera C, Butz S, Stadtmann A, Rossaint J, et al. GDF15 is an inhibitor of leukocyte integrin activation required for survival after myocardial infarction in mice. Nat Med. 2011;17(5):581-8.

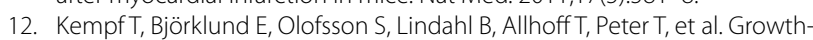
differentiation factor-15 improves risk stratification in ST-segment elevation myocardial infarction. Eur Heart J. 2007;28(23):2858-65.

13. Damman P, KempfT, Windhausen F, van Straalen JP, Guba-Quint A, Fischer J, et al. Growth-differentiation factor 15 for long-term prognostication in patients with non-ST-elevation acute coronary syndrome: an Invasive versus Conservative Treatment in Unstable coronary Syndromes (ICTUS) substudy. Int J Cardiol. 2014;172(2):356-63.

14. Lindholm D, James SK, Gabrysch K, Storey RF, Himmelmann A, Cannon $\mathrm{CP}$, et al. Association of multiple biomarkers with risk of all-cause and cause-specific mortality after acute coronary syndromes: a secondary analysis of the PLATO biomarker study. JAMA Cardiol. 2018;3(12):1160-6.

15. Wollert KC, Kempf T, Peter T, Olofsson S, James S, Johnston N, et al. Prognostic value of growth-differentiation factor-15 in patients with nonST-elevation acute coronary syndrome. Circulation. 2007;115(8):962-71.

16. Kyu HH, Abate D, Abate KH, Abay SM, Abbafati C, Abbasi N, Abbastabar H, Abd-Allah F, Abdela J, Abdelalim A, Abdollahpour I. Global, regional, and national disability-adjusted life-years (DALYs) for 359 diseases and injuries and healthy life expectancy (HALE) for 195 countries and territories, 1990-2017: a systematic analysis for the Global Burden of Disease Study 2017. Lancet. 2018;392(10159):1859-922.

17. Buffon A, Biasucci LM, Liuzzo G, D’Onofrio G, Crea F, Maseri A. Widespread coronary inflammation in unstable angina. N Engl J Med. 2002;347(1):5-12

18. Lombardo A, Biasucci LM, Lanza GA, Coli S, Silvestri P, Cianflone D, et al. Inflammation as a possible link between coronary and carotid plaque instability. Circulation. 2004;109(25):3158-63.

19. Moore KJ, Tabas I. Macrophages in the pathogenesis of atherosclerosis. Cell. 2011;145(3):341-55.

20. Dick SA, Epelman S. Chronic heart failure and inflammation: what do we really know? Circ Res. 2016;119(1):159-76.

21. Winzap P, Davies A, Klingenberg R, Obeid S, Roffi M, Mach F, et al. Diabetes and baseline glucose are associated with inflammation, left ventricular function and short- and long-term outcome in acute coronary syndromes: role of the novel biomarker Cyr 61. Cardiovasc Diabetol. 2019;18(1):142.

22. Rogacev KS, Cremers B, Zawada AM, Seiler S, Binder N, Ege P, et al. CD14++CD16 + monocytes independently predict cardiovascular events: a cohort study of 951 patients referred for elective coronary angiography. J Am Coll Cardiol. 2012;60(16):1512-20.

23. Horckmans M, Ring L, Duchene J, Santovito D, Schloss MJ, Drechsler $M$, et al. Neutrophils orchestrate post-myocardial infarction healing by polarizing macrophages towards a reparative phenotype. Eur Heart J. 2017;38(3):187-97.

24. Kozakova M, Morizzo C, Goncalves I, Natali A, Nilsson J, Palombo C. Cardiovascular organ damage in type 2 diabetes mellitus: the role of lipids and inflammation. Cardiovasc Diabetol. 2019;18(1):61. 
25. Schlittenhardt D, Schober A, Strelau J, Bonaterra GA, Schmiedt W, Unsicker K, et al. Involvement of growth differentiation factor-15/ macrophage inhibitory cytokine-1 (GDF-15/MIC-1) in oxLDL-induced apoptosis of human macrophages in vitro and in arteriosclerotic lesions. Cell Tissue Res. 2004;318(2):325-33.

26. Abulizi P, Loganathan N, Zhao D, Mele T, Zhang Y, Zwiep T, et al. Growth differentiation factor-15 deficiency augments inflammatory response and exacerbates septic heart and renal injury induced by lipopolysaccharide. Sci Rep. 2017;7(1):1037.

27. Verhamme FM, Seys LJM, De Smet EG, Provoost S, Janssens W, Elewaut $D$, et al. Elevated GDF-15 contributes to pulmonary inflammation upon cigarette smoke exposure. Mucosal Immunol. 2017;10(6):1400-11.

28. Wang A, Huen SC, Luan HH, Yu S, Zhang C, Gallezot J-D, et al. Opposing effects of fasting metabolism on tissue tolerance in bacterial and viral inflammation. Cell. 2016;166(6):1512-25.

29. KempfT, Eden M, Strelau J, Naguib M, Willenbockel C, Tongers J, et al. The transforming growth factor-beta superfamily member growth-differentiation factor-15 protects the heart from ischemia/reperfusion injury. Circ Res. 2006;98(3):351-60.

30. Koopmann J, Buckhaults P, Brown DA, Zahurak ML, Sato N, Fukushima N, et al. Serum macrophage inhibitory cytokine 1 as a marker of pancreatic and other periampullary cancers. Clin Cancer Res. 2004;10(7):2386-92.

31. Tan M, Wang Y, Guan K, Sun Y. PTGF-beta, a type beta transforming growth factor (TGF-beta) superfamily member, is a p53 target gene that inhibits tumor cell growth via TGF-beta signaling pathway. Proc Natl Acad Sci USA. 2000;97(1):109-14.

32. Bauskin AR, Brown DA, Junankar S, Rasiah KK, Eggleton S, Hunter M, et al. The propeptide mediates formation of stromal stores of PROMIC-1: role in determining prostate cancer outcome. Cancer Res. 2005;65(6):2330-6.

33. Jung S-B, Choi MJ, Ryu D, Yi H-S, Lee SE, Chang JY, et al. Reduced oxidative capacity in macrophages results in systemic insulin resistance. Nat Commun. 2018;9(1):1551.

34. Haring R, Völzke H, Steveling A, Krebs A, Felix SB, Schöfl C, et al. Low serum testosterone levels are associated with increased risk of mortality in a population-based cohort of men aged 20-79. Eur Heart J. 2010;31(12):1494-501.

35. Liu H, Lyu Y, Li D, Cui Y, Huang Y, Dai W, et al. Potential relation between soluble growth differentiation factor-15 and testosterone deficiency in male patients with coronary artery disease. Cardiovasc Diabetol. 2019;18(1):21.

36. Laughlin GA, Barrett-Connor E, Bergstrom J. Low serum testosterone and mortality in older men. J Clin Endocrinol Metabol. 2008;93(1):68-75.

37. Sharma A, Hijazi Z, Andersson U, Al-Khatib SM, Lopes RD, Alexander JH, et al. Use of biomarkers to predict specific causes of death in patients with atrial fibrillation. Circulation. 2018;138(16):1666-76.
38. Bouabdallaoui N, Claggett B, Zile MR, McMurray JJV, O'Meara E, Packer M, et al. Growth differentiation factor-15 is not modified by sacubitril/valsartan and is an independent marker of risk in patients with heart failure and reduced ejection fraction: the PARADIGM-HF trial. Eur J Heart Fail. 2018;20(12):1701-9.

39. Meloux A, Rochette L, Maza M, Bichat F, Vergely C. Growth differentiation factor 15 as an integrative biomarker of heart failure in patients with acute myocardial infarction. Arch Cardiovas Dis Suppl. 2019;11(1):45.

40. Daniels LB, Clopton P, Laughlin GA, Maisel AS, Barrett-Connor E. Growthdifferentiation factor-15 is a robust, independent predictor of 11-year mortality risk in community-dwelling older adults: the Rancho Bernardo Study. Circulation. 2011;123(19):2101-10.

41. Kempf T, von Haehling S, Peter T, AllhoffT, Cicoira M, Doehner W, et al. Prognostic utility of growth differentiation factor-15 in patients with chronic heart failure. J Am Coll Cardiol. 2007;50(11):1054-60.

42. Berezin AE. Growth differentiation factor 15 in cardiovascular diseases: are we needed novel biomarker? Vasc Dis Prev. 2018;2(1):1-2.

43. Rohatgi A, Patel P, Das SR, Ayers CR, Khera A, Martinez-Rumayor A, et al. Association of growth differentiation factor-15 with coronary atherosclerosis and mortality in a young, multiethnic population: observations from the Dallas Heart Study. Clin Chem. 2012;58(1):172-82.

44. Khan SQ, Ng K, Dhillon O, Kelly D, Quinn P, Squire IB, et al. Growth differentiation factor-15 as a prognostic marker in patients with acute myocardial infarction. Eur Heart J. 2009;30(9):1057-65.

45. Bonaca MP, Morrow DA, Braunwald E, Cannon CP, Jiang S, Breher S, et al Growth differentiation factor-15 and risk of recurrent events in patients stabilized after acute coronary syndrome: observations from PROVE ITTIMI 22. Arterioscler Thromb Vasc Biol. 2011;31(1):203-10.

46. Kempf T, Sinning J-M, Quint A, Bickel C, Sinning C, Wild PS, et al. Growthdifferentiation factor-15 for risk stratification in patients with stable and unstable coronary heart disease: results from the AtheroGene study. Circ Cardiovasc Genetics. 2009;2(3):286-92.

47. Hagström E, Held C, Stewart RAH, Aylward PE, Budaj A, Cannon CP, et al. Growth differentiation factor 15 predicts all-cause morbidity and mortality in stable coronary heart disease. Clin Chem. 2017;63(1):325-33.

\section{Publisher's Note}

Springer Nature remains neutral with regard to jurisdictional claims in published maps and institutional affiliations.

Ready to submit your research? Choose BMC and benefit from:

- fast, convenient online submission

- thorough peer review by experienced researchers in your field

- rapid publication on acceptance

- support for research data, including large and complex data types

- gold Open Access which fosters wider collaboration and increased citations

- maximum visibility for your research: over $100 \mathrm{M}$ website views per year

At BMC, research is always in progress.

Learn more biomedcentral.com/submissions 